\title{
Induced regulatory T cells in allograft tolerance via transient mixed chimerism
}

\author{
Kiyohiko Hotta, ${ }^{1}$ Akihiro Aoyama, ${ }^{1}$ Tetsu Oura, ${ }^{1}$ Yohei Yamada, ${ }^{1}$ Makoto Tonsho, ${ }^{1}$ Kyu Ha Huh, ${ }^{1}$ \\ Kento Kawai, ${ }^{1}$ David Schoenfeld, ${ }^{2}$ James S. Allan, ${ }^{1}$ Joren C. Madsen, ${ }^{1}$ Gilles Benichou, ${ }^{1}$ \\ Rex-Neal Smith, ${ }^{3}$ Robert B. Colvin, ${ }^{3}$ David H. Sachs, ${ }^{1}$ A. Benedict Cosimi, ${ }^{1}$ and Tatsuo Kawai' \\ 'Department of Surgery, Center for Transplantation Sciences, Massachusetts General Hospital and Harvard Medical \\ School, Boston, Massachusetts, USA. ${ }^{2}$ Department of Biostatistics, Massachusetts General Hospital, Boston, \\ Massachusetts, USA. ${ }^{3}$ Department of Pathology, Massachusetts General Hospital and Harvard Medical School, \\ Boston, Massachusetts, USA.
}

\begin{abstract}
Successful induction of allograft tolerance has been achieved in nonhuman primates (NHPs) and humans via induction of transient hematopoietic chimerism. Since allograft tolerance was achieved in these recipients without durable chimerism, peripheral mechanisms are postulated to play a major role. Here, we report our studies of T cell immunity in NHP recipients that achieved long-term tolerance versus those that rejected the allograft (AR). All kidney, heart, and lung transplant recipients underwent simultaneous or delayed donor bone marrow transplantation (DBMT) following conditioning with a nonmyeloablative regimen. After DBMT, mixed lymphocyte culture with CFSE consistently revealed donor-specific loss of CD8 ${ }^{+} \mathrm{T}$ cell responses in tolerant (TOL) recipients, while marked CD4 ${ }^{+} \mathrm{T}$ cell proliferation in response to donor antigens was found to persist. Interestingly, a significant proportion of the proliferated $\mathrm{CD4}^{+}$cells were $\mathrm{FOXP3}^{+}$in $\mathrm{TOL}$ recipients, but not in $A R$ or naive NHPs. In TOL recipients, $\mathrm{CD}^{+}{ }^{+} \mathrm{FXP3}^{+}$cell proliferation against donor antigens was greater than that observed against third-party antigens. Finally, the expanded Tregs appeared to be induced Tregs (iTregs) that were converted from non-Tregs. These data provide support for the hypothesis that specific induction of iTregs by donor antigens is key to long-term allograft tolerance induced by transient mixed chimerism.
\end{abstract}

Authorship note: K. Hotta and A. Aoyama contributed equally to this work.

Conflict of interest: The authors have declared that no conflict of interest exists.

Submitted: January 13, 2016

Accepted: June 2, 2016

Published: July 7, 2016

Reference information:

JCI Insight. 2016;1(10):e86419.

doi:10.1172/jci.insight.86419.

\section{Introduction}

The development of effective immunosuppressive agents has significantly improved short-term outcomes following organ transplantation. However, long-term administration of these medications is associated with various side effects, which significantly increase morbidity and mortality in transplant recipients. Moreover, despite having powerful immunosuppressive effects, these medications often fail to prevent the development of chronic rejection, which eventually leads to graft loss (1-3). Induction of tolerance could potentially overcome these limitations by eliminating the requirement for maintenance immunosuppression, thereby improving the long-term results of organ transplantation. We have previously reported a nonmyeloablative conditioning regimen for combined kidney and bone marrow transplantation (CKBMT) that is capable of inducing mixed chimerism and renal allograft tolerance in nonhuman primates (NHPs) (4-6). The protocol has been successfully translated to human recipients of both HLA-matched and HLAmismatched kidney transplants (7-10). An analogous protocol has also been used successfully to induce tolerance in NHP lung transplantation (11).

In earlier murine studies, induction of durable mixed chimerism was required for induction of MHC fully mismatched skin allograft tolerance (12). Stable chimerism in those studies led to persistent deletion of anti-donor $\mathrm{T}$ cells in the thymus, while transient chimerism failed to induce skin allograft tolerance (13-15). However, when similar nonmyeloablative conditioning regimens were used in NHPs and humans, only transient mixed chimerism was achieved, and it typically became undetectable within 1 or 2 months after donor bone marrow transplantation (DBMT). The pretransplant presence of heterologous memory $\mathrm{T}$ cells, and more significantly, the peri-transplant inflammatory responses observed in NHPs and humans, may contribute to the difficulty of inducing durable chimerism in this population $(16,17)$. Nevertheless, the majority of NHP and human recipients achieved long-term renal allograft tolerance despite the loss of 
Table 1. Nonhuman primate study subjects

\begin{tabular}{|c|c|c|c|c|c|}
\hline Group & Monkey \# & Allograft & Chimerism & Graft Survival' & Histology \\
\hline \multirow[t]{9}{*}{ TOL } & M3312 & Kidney & + & $>446$ & NDAR \\
\hline & M4808 & Kidney & + & $>728$ & NDAR \\
\hline & M8907 & Kidney & + & $>996$ & NDAR \\
\hline & M3208 & Kidney & + & $>791$ & No ACR, TG, CUO \\
\hline & M6007 & Kidney & + & $>1133$ & No ACR, TG \\
\hline & M8014 & Kidney & $++^{\mathrm{B}}$ & $>250$ & NDAR \\
\hline & M8314 & Kidneyc & + & $>270$ & NDAR \\
\hline & M912 & Lung & + & $>464$ & NDAR \\
\hline & M4012 & Lung & + & $>299$ & NDAR \\
\hline \multirow[t]{8}{*}{ AR } & M406 & Kidney & - & 47 & $A C R$ \\
\hline & M1009 & Kidney & ND & 62 & $A C R$ \\
\hline & M913 & Kidney & - & 124 & ACR \\
\hline & M4514 & Kidney & + & 127 & $A C R$ \\
\hline & M5114 & Kidney & $++^{\mathrm{D}}$ & 345 & $A C R$ \\
\hline & M4609 & Heart & ND & 117 & $A C R$ \\
\hline & М3113 & Heart & $+^{\mathrm{B}}$ & 151 & $A C R$ \\
\hline & M5212 & Heart & $t^{B}$ & 147 & $A C R$ \\
\hline
\end{tabular}

ADays after bone marrow transplantation. ${ }^{B}$ Myeloid chimerism alone. ${ }^{C}$ Heart allograft from the same donor was also cotransplanted.

Detected by PCR. ND, not determined; NDAR, no diagnostic abnormality; ACR, acute cellular rejection; TC, transplant glomerulopathy; CUO, chronic ureteral obstruction.

hematopoietic chimerism $(4-6,8,10)$. Since the chimerism was transient, we postulated that peripheral tolerance, rather than central deletion, was the major pathway for induction and maintenance of renal allograft tolerance. Unfortunately, little is known to date about precise mechanisms of allograft tolerance after induction of transient chimerism in NHPs and humans. In clinical trials, transient enrichment of Tregs in the peripheral blood (18) and significantly higher FOXP3 mRNA in renal allografts (8) have been found in tolerant recipients, but the immunological significance of these findings is not known. Although we recently reported a trend of reduction in the number of donor-reactive $\mathrm{T}$ cell clones in the tolerant recipients (19), substantial numbers of donor-reactive clones were still detectable. The critical importance of regulatory mechanisms of tolerance was also supported by our recent studies demonstrating that stable renal allograft tolerance induced in NHPs after transient hematopoietic chimerism could be abrogated by IL-2 infusion (20).

To further elucidate the mechanism of long-term allograft tolerance via this approach, we compared $\mathrm{T}$ cell immunity in NHP recipients that achieved long-term renal or lung allograft survival to that observed in NHPs that rejected their allograft.

\section{Results}

Renal and lung allograft tolerance induced by transient multilineage chimerism. Seven kidney and 2 lung allograft NHP recipients that achieved long-term (>250 days) transplant survival without maintenance immunosuppression (TOL) were evaluated in the current mechanistic studies (Table 1 and Figure 1). The transplant outcome of these recipients has been reported previously (11,21-23). After conditioning, recipients developed transient pancytopenia, which recovered by day 30 in the lymphoid cells and by day 20 in the myeloid cells (Figure 2A). Eight of the 9 recipients developed multilineage transient chimerism, while 1 recipient (M8014) developed chimerism only in the myeloid lineage (Figure 2B and Table 1). Except for M4012, which received the lung allograft and developed persistent chimerism for more than 2 years (Figure 2C), chimerism typically became undetectable by flow cytometry by day 100. Although M3208 and M6007 developed minor transplant glomerulopathy with low anti-B cell donor-specific antibodies (DSAs), no diagnostic abnormality was found in the kidney or lung allografts of the other 7 recipients (Figure 2, D and $\mathrm{E}$, and Table 1). For comparison, we included 5 kidney recipients that had rejected the allograft despite receiving the same conditioning regimen. Since heart allograft recipients receiving the same treatment and DBMT consistently failed to acquire tolerance despite successful induction of comparable chimerism (24), 


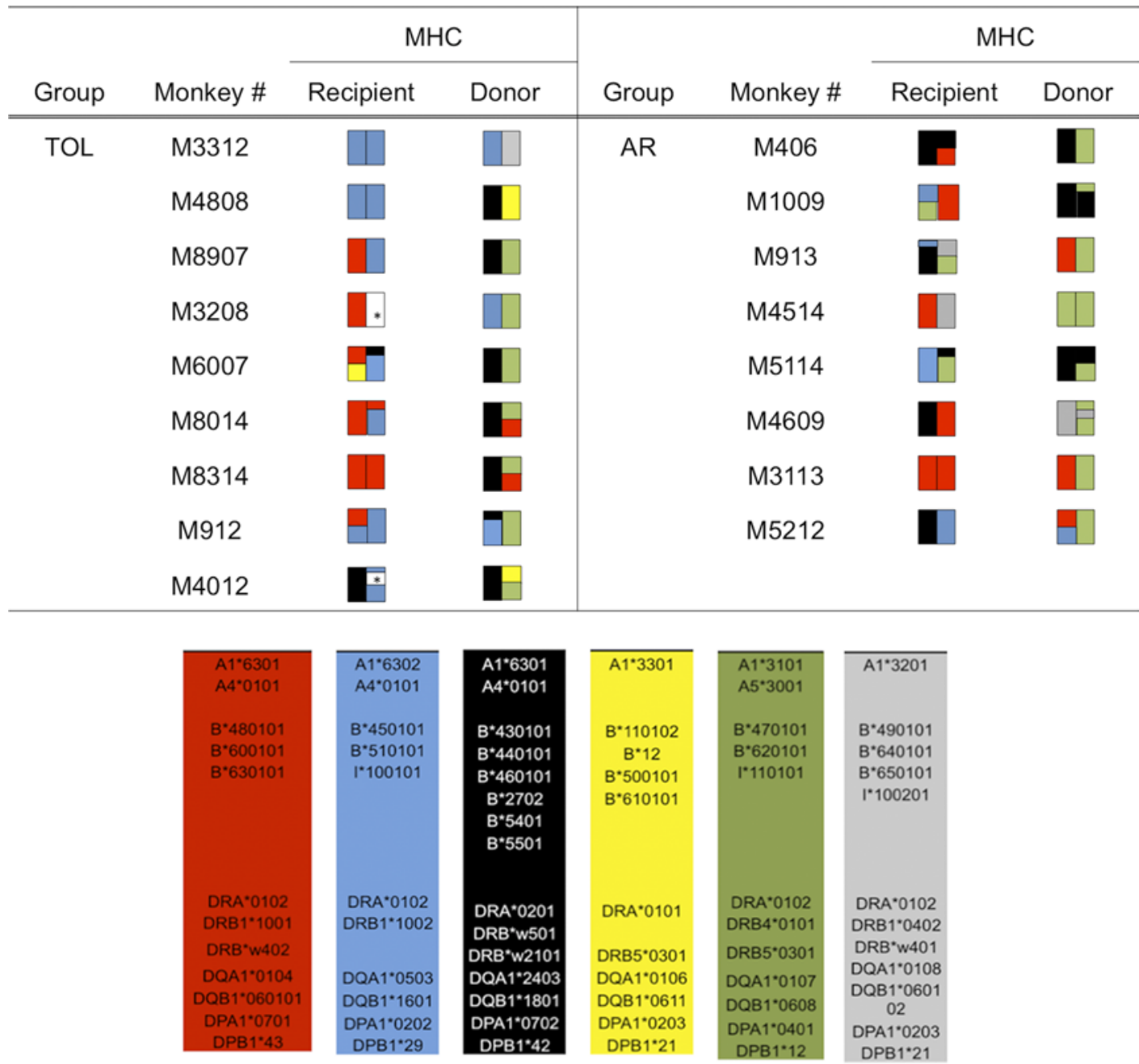

Figure 1. MHC genotypes of donor-recipient pairs. The MHC class I (A and B loci) and II (DP, DQ, and DR loci) genes expressed by each recipient monkey and its respective donor are shown and color coded to highlight allelic differences. ${ }^{*}$ Not identified. TOL, tolerant recipient; AR, recipients that developed acute rejection.

we also included 3 heterotopic heart recipients that lost their allografts due to acute rejection (AR). In the AR recipients, multilineage chimerism was detectable in only 1 recipient (M4514) (Table 1 and Figure 1).

Peripheral blood lymphocyte subsets among the TOL, AR, and naive NHPs. We first characterized the makeup of the peripheral blood lymphocyte (PBL) subsets in TOL, AR, and naive recipients. The study revealed no significant difference in the number of $\mathrm{CD}^{+} \mathrm{CD}^{+} \mathrm{T}$ cells, $\mathrm{CD}^{+} \mathrm{CD}^{+} \mathrm{T}$ cells, $\mathrm{B}$ cells $\left(\mathrm{CD} 3^{-} \mathrm{CD} 20^{+}\right)$, or Tregs $\left(\mathrm{CD}^{+} \mathrm{CD}^{2} 5^{+} \mathrm{FOXP}^{+}\right)$in the peripheral blood of TOL, AR, and naive recipients (Figure 3, A-C, E, and $\mathrm{F})$. In contrast, the number of $\mathrm{NK}$ cells $\left(\mathrm{CD} 3^{-} \mathrm{CD} 8^{+} \mathrm{CD} 16^{+} \mathrm{NKG} 2 \mathrm{a}^{+}\right)$was significantly lower in TOL recipients compared with naive NHPs (Figure 3D).

Sustained anti-donor $\mathrm{CD}^{+} \mathrm{T}$ cell responses in the tolerant recipients despite loss of anti-donor $\mathrm{CD} 8^{+} \mathrm{T}$ cell responses. We next evaluated $\mathrm{T}$ cell responses against donor antigens in both TOL and $\mathrm{AR}$ recipients and compared them with the $\mathrm{T}$ cell responses of naive NHPs against MHC-mismatched allogeneic antigens. Isolated $\mathrm{CD}^{+}$cells were labeled with carboxyfluorescein succinimidyl ester (CFSE) and cultured with irradiated self or donor PBLs for 5 days, after which the cultured cells were stained for CD4 and CD8 for flow cytometric analysis. Anti-donor $\mathrm{CD}^{+} \mathrm{T}$ cell responses were found to be significantly lower in TOL compared with AR recipients $(P<0.05)$ (Figure 4 , A and B). In contrast, marked CD4 ${ }^{+} \mathrm{T}$ cell proliferation was observed after mixed lymphocyte culture (MLC) with donor PBLs in TOL recipients, comparable to that observed in both the AR and naive NHPs (Figure 4, C and D).

Tregs expanded in donor-specific fashion in the tolerant recipients. To further identify which $\mathrm{CD} 4^{+} \mathrm{T}$ cell subsets were expanding, responder T cells were also stained for INF- $\gamma$, IL-4, IL-17, and FOXP3. Although 
A Peripheral blood cell counts

Lymphoid cells

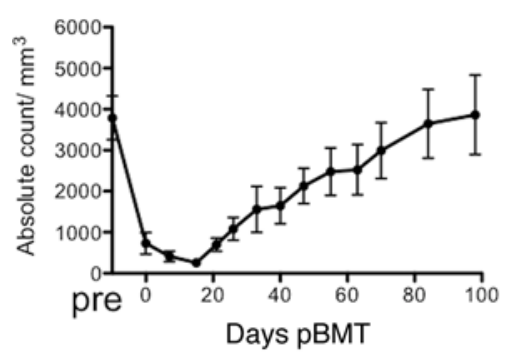

B Kidney

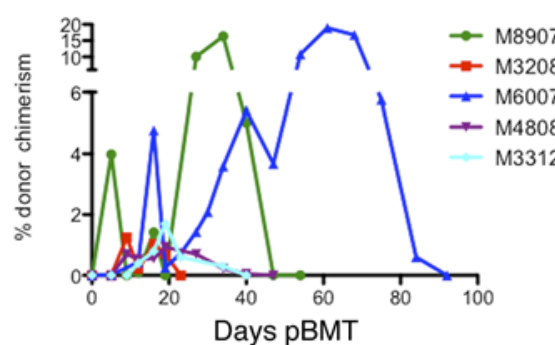

C Lung Lymphoid lineage

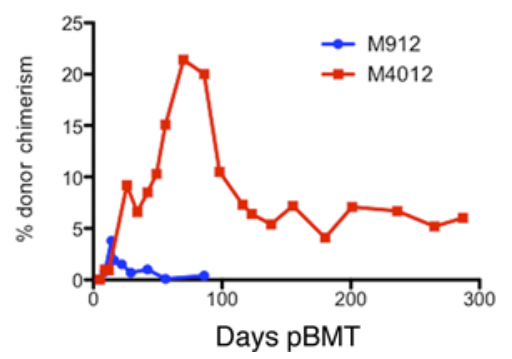

Myeloid cells
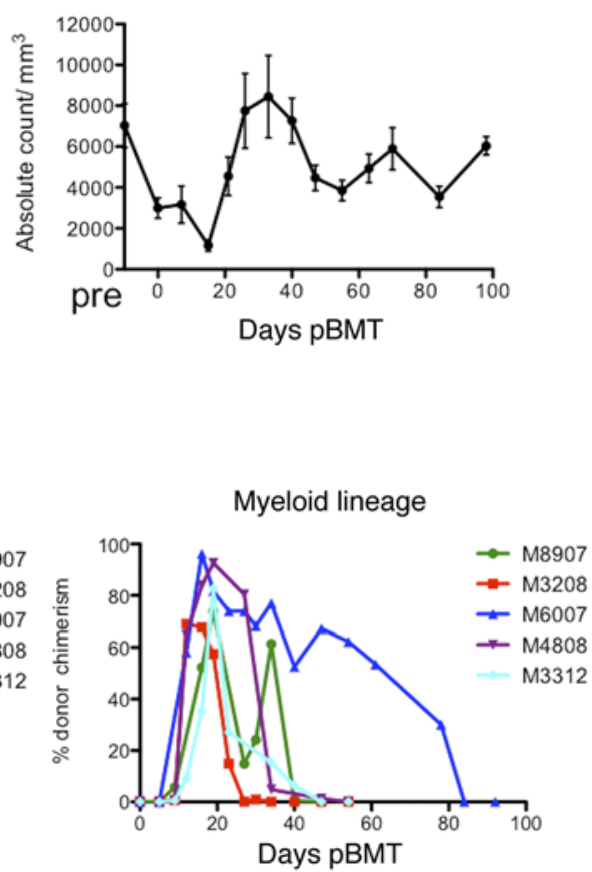

Myeloid lineage

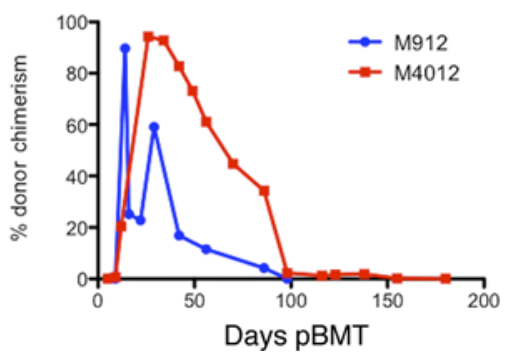

D Kidney

M4808 d307 pBMT M3312 d449 pBMT

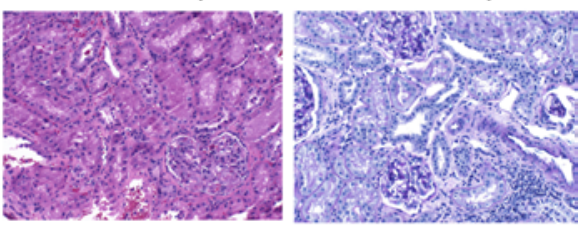

E Lung

M912 d464 pBMT $\quad$ M4012 d299 pBMT

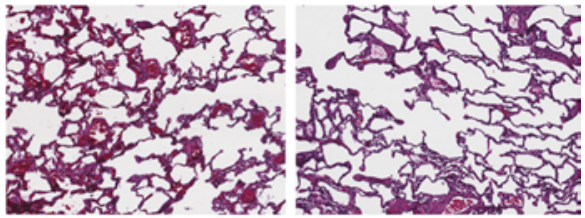

Figure 2. Chimerism and histopathology of allografts in the tolerant recipients. After conditioning, recipients developed transient pancytopenia but recovered by day 30 in the lymphoid cells and by day 20 in the myeloid cells (A); $n=9$. Tolerant (TOL) recipients of kidney (B) and lung (C) allografts developed multilineage chimerism in both lymphoid and myeloid lineages. Chimerism in these recipients typically disappeared by day 60 after donor bone marrow transplantation, except for M4012 whose lymphoid chimerism remained detectable (around $5 \%$ ) until his euthanasia on day 299. Representative biopsies or autopsies of the kidney (D) and the lung allografts (E) in the TOL recipients are shown. No diagnostic abnormality was found in either the kidney or lung allografts. Original magnification, $\times 100$.

expression of INF- $\gamma$, IL-4, and IL-17 was limited (data not shown), a significantly higher proportion of the proliferating $\mathrm{CD}^{+}$cells were $\mathrm{FOXP}^{+}$in TOL recipients, as compared to those in the AR and naive NHPs $(P<0.05)$ (Figure 5, A and B). Additionally, we evaluated $\mathrm{T}$ cell responses after polyclonal stimulation (anti-CD2/CD3/CD28 mAb) among the 3 groups. Similar Treg expansion was not observed with polyclonal stimulation, suggesting that alloantigen stimulation is essential for Treg expansion (Figure 5, C and D). To evaluate whether the Treg expansion observed in TOL was donor specific, isolated T cells from 7 TOL recipients were cultured with irradiated self, donor, and multiple third-party PBLs. The study revealed significantly greater $\mathrm{FOXP}^{+}$cell proliferation observed after MLC with donor PBLs compared with thirdparty PBLs $(P<0.001)$ (Figure 5E).

The expanded Tregs after donor stimulation were derived from non-Treg cells. To identify the origin of the expanded Tregs observed in the TOL recipients, we next performed a CFSE/MLC assay with sorted $\mathrm{CD} 4^{+} \mathrm{CD} 25^{\text {high }}$ cells (Tregs) and $\mathrm{CD} 4^{+} \mathrm{CD} 25^{-}$cells (non-Tregs), in which the proportion of $\mathrm{FOXP}^{+}$cells was greater than $90 \%$ and less than $0.9 \%$, respectively (Figure $6 \mathrm{~A}$ ). $\mathrm{CD} 4^{+} \mathrm{CD} 25^{-}$cells (non-Tregs) were mixed populations of naive $\left(\mathrm{CD} 4^{+} \mathrm{CD} 95^{-} \mathrm{CD} 28^{+}\right)$, effector memory $\left(\mathrm{CD} 4^{+} \mathrm{CD} 95^{+} \mathrm{CD} 28^{-}\right)$, and central memory $\left(\mathrm{CD} 4{ }^{+} \mathrm{CD} 95^{+} \mathrm{CD} 28^{+}\right) \mathrm{T}$ cells (data not shown). Sorted Tregs and non-Tregs from 2 TOL recipients (M4012 and M3312) were labeled with CFSE and cultured with irradiated donor PBLs in the presence of IL-2 (200 IU/ml). No significant FOXP3 $3^{+}$cell proliferation was observed in MLC of CD4 $4^{+} \mathrm{CD} 25^{\text {high }}$ cells with donor stimulation in either recipient (Figure 6B). In contrast, substantial FOXP3 ${ }^{+}$cell proliferation was observed in MLC of $\mathrm{CD}^{+} \mathrm{CD} 25^{-}$cells in both recipients (Figure 6B), suggesting that the Tregs 
A

Lymphocytes

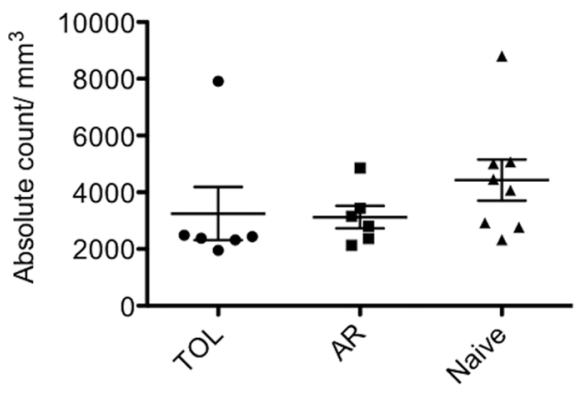

D

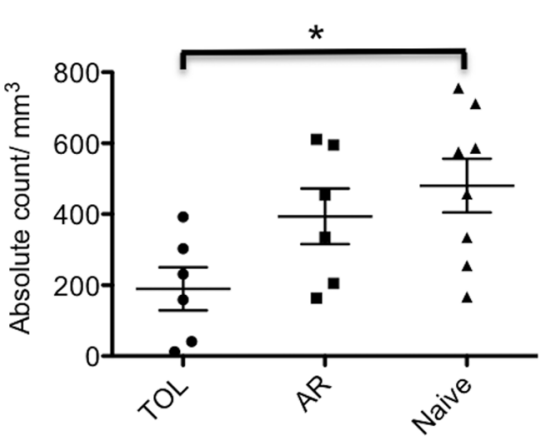

B

$\mathrm{CD}^{+}{ }^{+} \mathrm{T}$ cells
C

$\mathrm{CD}^{+}{ }^{+} \mathrm{T}$ cells

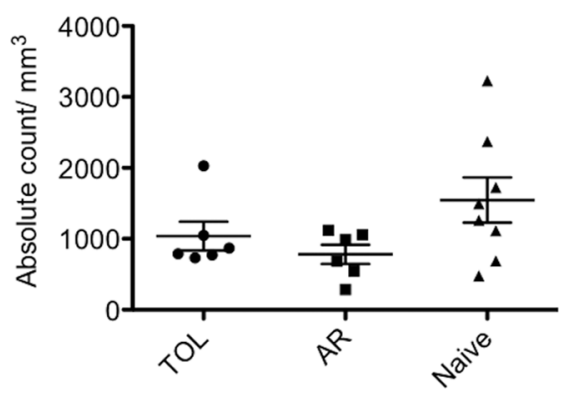

E

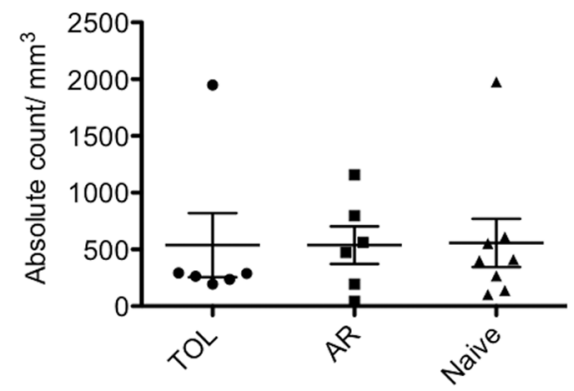

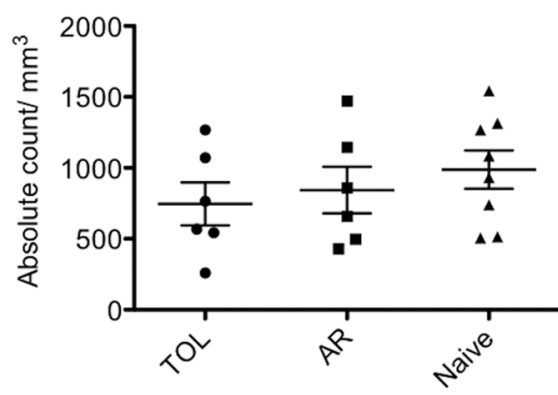

$\mathbf{F}$

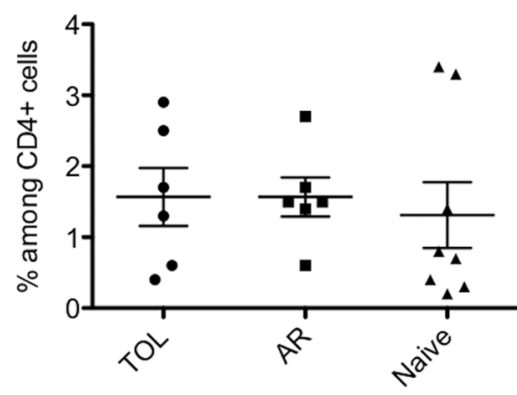

Figure 3. Lymphocyte subsets in the peripheral blood in tolerant, rejected, and naive nonhuman primates. The number of $(A)$ lymphocytes, (B) $C D 3^{+} C D 8{ }^{+}$

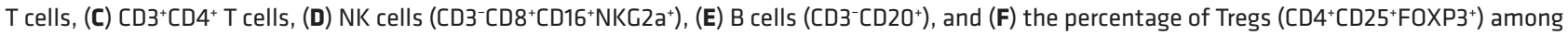
peripheral $\mathrm{CD} 4^{+} \mathrm{T}$ cells. There was no significant difference in the number of lymphocytes, $\mathrm{CD} 8^{+} \mathrm{T}$ cells, $\mathrm{CD} 4^{+} \mathrm{T}$ cells, $\mathrm{B}$ cells, and Tregs in the peripheral blood among tolerant (TOL), acutely rejected (AR), and naive nonhuman primates (NHPs). The number of NK cells was significantly lower in tolerant NHPs compared to naive NHPs. These assays were performed at $516 \pm 179$ days in the TOL recipients and $165 \pm 42$ days in the AR recipients after bone marrow transplantation. Data are presented as the mean \pm SEM. ${ }^{*} P<0.05$, ANOVA and the Bonferroni multiple-comparison method was used to test for significant differences among 3 groups; $n=6-8$ per group.

proliferating after donor antigen stimulation were induced Tregs (iTregs) converted from non-Tregs. We also tested whether such Treg conversion could be observed by polyclonal $\alpha \mathrm{CD} 2 / \alpha \mathrm{CD} 3 / \alpha \mathrm{CD} 28 \mathrm{mAb}$ stimulation. Although significant $\mathrm{FOXP} 3^{+}$cell expansion was observed from $\mathrm{CD} 4{ }^{+} \mathrm{CD} 25^{\text {high }}$ cells, conversion from non-Treg to Treg was not observed with the polyclonal stimulation (Figure 6C). Finally, we sorted non-Tregs from 2 AR recipients (M4514 and M5114) and performed a CFSE/MLC assay with donor-antigen stimulation. Unlike tolerant NHPs, no iTreg conversion was observed with either donor or polyclonal stimulation (Figure 6, D and E).

TGF- $\beta$ blockade inhibited Treg expansion and restored CD8 responses. To further elucidate the underlying mechanisms of the Treg expansion observed in TOL recipients, we performed a CFSE/MLC assay with an anti-TGF- $\beta$ monoclonal antibody. Isolated $\mathrm{CD}^{+}$cells from 2 TOL recipients (M8014 and M8314) were labeled with CFSE and cultured with irradiated donor PBLs in the presence of anti-TGF- $\beta$ or isotype control monoclonal antibody. Inhibition of Treg expansion by TGF- $\beta$ blockade was observed in both TOL recipients tested (Figure 7, A and B, CD4 gated). Interestingly, inhibition of Treg expansion was associated with restoration of $\mathrm{CD} 8^{+} \mathrm{T}$ cell responses in both recipients (Figure 7, $\mathrm{A}$ and $\mathrm{B}, \mathrm{CD} 8$ gated). These results suggest that TGF- $\beta$ is a critical cytokine for iTreg expansion, which renders inhibition of anti-donor CD $8^{+}$ $\mathrm{T}$ cell responses.

Proliferated cells after MLC with donor antigens suppressed T cell activation via cell-to-cell contact. In the final experiment, we evaluated the suppressive function of T cells after MLC in 3 tolerant NHPs (M8907, M6007, and M8314). Although specific expansion of Tregs was consistently observed in TOL recipients, expansion of non-Tregs was also observed. Therefore, we evaluated the net immunological effect of the entire proliferated $\mathrm{T}$ cell population after donor or third-party stimulation. In this functional assay, we first stimulated PBLs with donor or third-party antigens and then evaluated the suppressive function of $\mathrm{CD}^{+}$proliferated or nonproliferated cells. To test the suppressive function of PBLs after MLC, we chose 
A TOL (M3312)
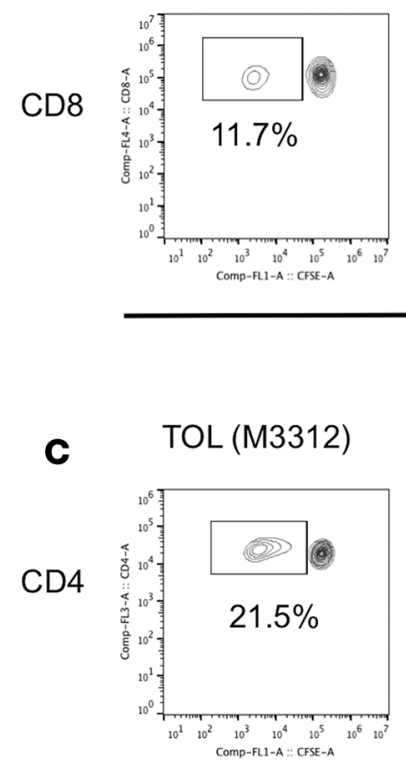

AR (M1009)

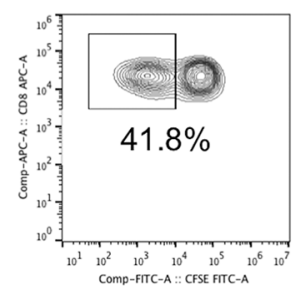

CFSE
Naive

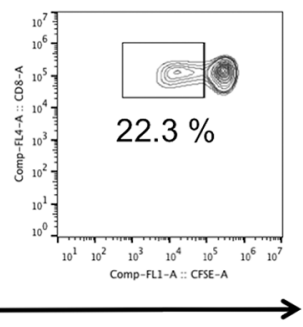

AR (M1009)

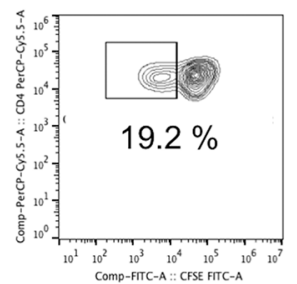

CFSE
B $\quad$ CD8+

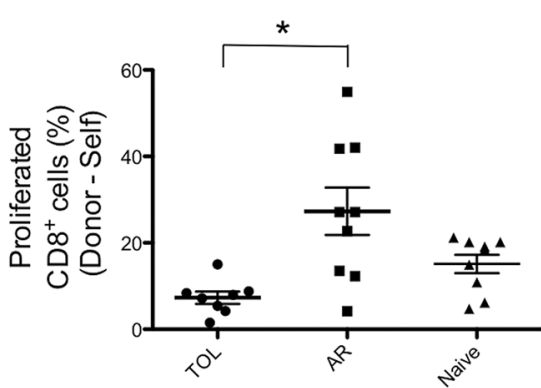

D CD4+

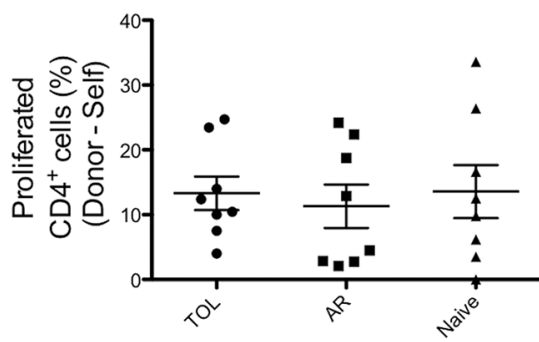

Figure 4. Loss of anti-donor $\mathrm{CD8}{ }^{+} \mathrm{T}$ cell responses despite substantial anti-donor $\mathrm{CD} 4^{+} \mathrm{T}$ cell responses in tolerant recipients. The $\mathrm{CD3^{+ }}$ cells isolated from tolerant (TOL), acutely rejected (AR), and naive nonhuman primates (NHPs) were labeled with CFSE and were cultured with irradiated self or donor peripheral blood lymphocytes (PBLs) for 5 days. Naive T cells were cultured with irradiated MHC-mismatched PBLs. Cultured cells were then stained for CD4 and CD8. Representative flow cytometric data (A, CD8; C, CD4) and mean of \% proliferation relative to the response to the self (B, CD8; $\mathbf{D}, \mathrm{CD} 4)$ are shown. Anti-donor CD8 ${ }^{+} T$ cell hyporesponsiveness was observed in the TOL recipients, which was significantly lower than those observed in the AR recipients (A and B). However, substantial anti-donor CD4+ $T$ cell proliferation was observed in TOL, which was comparable to that observed in the AR and naive NHPs (C and D). Proliferated cells (\%) = proliferated cells (\%) with donor antigens - proliferated cells (\%) with the self. These assays were performed at 520 \pm 86 days in the TOL recipients and $175 \pm 37$ days in the AR recipients after bone marrow transplantation. Data are presented as the mean \pm SEM. ${ }^{*} P<0.05$, ANOVA and the Bonferroni multiple-comparison method was used to test for significant differences among 3 groups; $n=8$ per group.

to evaluate inhibition of $\mathrm{T}$ cell activation by anti-CD3/CD28 beads, since $\mathrm{T}$ cell responses against alloantigens were neither sufficiently consistent nor robust. Two recipients (M8907 and M6007) demonstrated dose-dependent suppression of $\mathrm{T}$ cell activation by the donor-primed proliferating cells (Figure 8, A and B). Although the suppression was less remarkable, the third-party-primed proliferating cells of 1 recipient (M8907) also showed dose-dependent suppression of T cell activation (Figure 8A). In contrast, no suppression was observed with donor or third-party-primed nonproliferating cells (Figure 8, A and B).

In the third recipient, we evaluated whether the suppressive function of the donor-primed $\mathrm{CD} 4^{+}$proliferating cells depends on cell-to-cell contact. Isolated $\mathrm{CD}^{+}$cells from a TOL recipient (M8314) stained with CFSE were cultured with anti-CD2/CD3/CD28 beads with donor-primed proliferating $\mathrm{CD} 4^{+}$cells added either directly (contact) or by seeding onto Transwell permeable support cell culture inserts (no contact). Although inhibition of $\mathrm{CD} 8^{+} \mathrm{T}$ cell proliferation was observed by direct contact with donor-primed $\mathrm{CD} 4^{+}$ proliferating cells, no suppression was observed in the Transwell system (Figure 8C). These results may indicate that suppression by donor-primed proliferating $\mathrm{CD} 4^{+}$cells requires cell-to-cell contact.

\section{Discussion}

A number of studies have associated increased levels of peripheral blood or allograft-infiltrated Tregs with better clinical outcomes following kidney transplantation (25-27). In our NHP studies, however, with the exception of NK cells, which were significantly lower in TOL recipients, we found no significant differences between the PBL subsets. Significantly lower NK cells in TOL recipients was unexpected and remains a matter for future investigation. Since we have previously observed Treg enrichment during the leukopenic period in TOL recipients $(6,28)$, it was also unexpected to us that there was no significant difference in the number of peripheral blood $\mathrm{CD} 4^{+} \mathrm{FOXP}^{+}$cells among the TOL, AR, and naive recipients after recovery from leukopenia. Since our previous swine and human studies elicited a distinct 
A

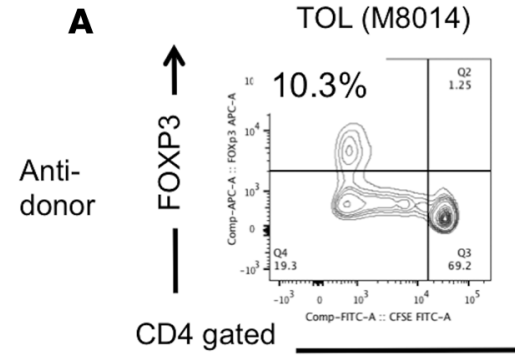

AR (M4514)

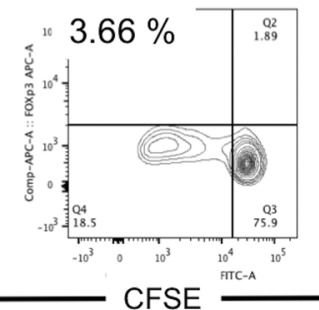

Naive

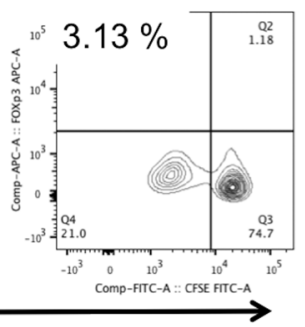

Naive

\section{C}

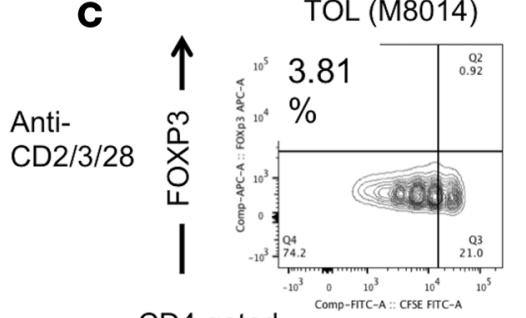

CD4 gated
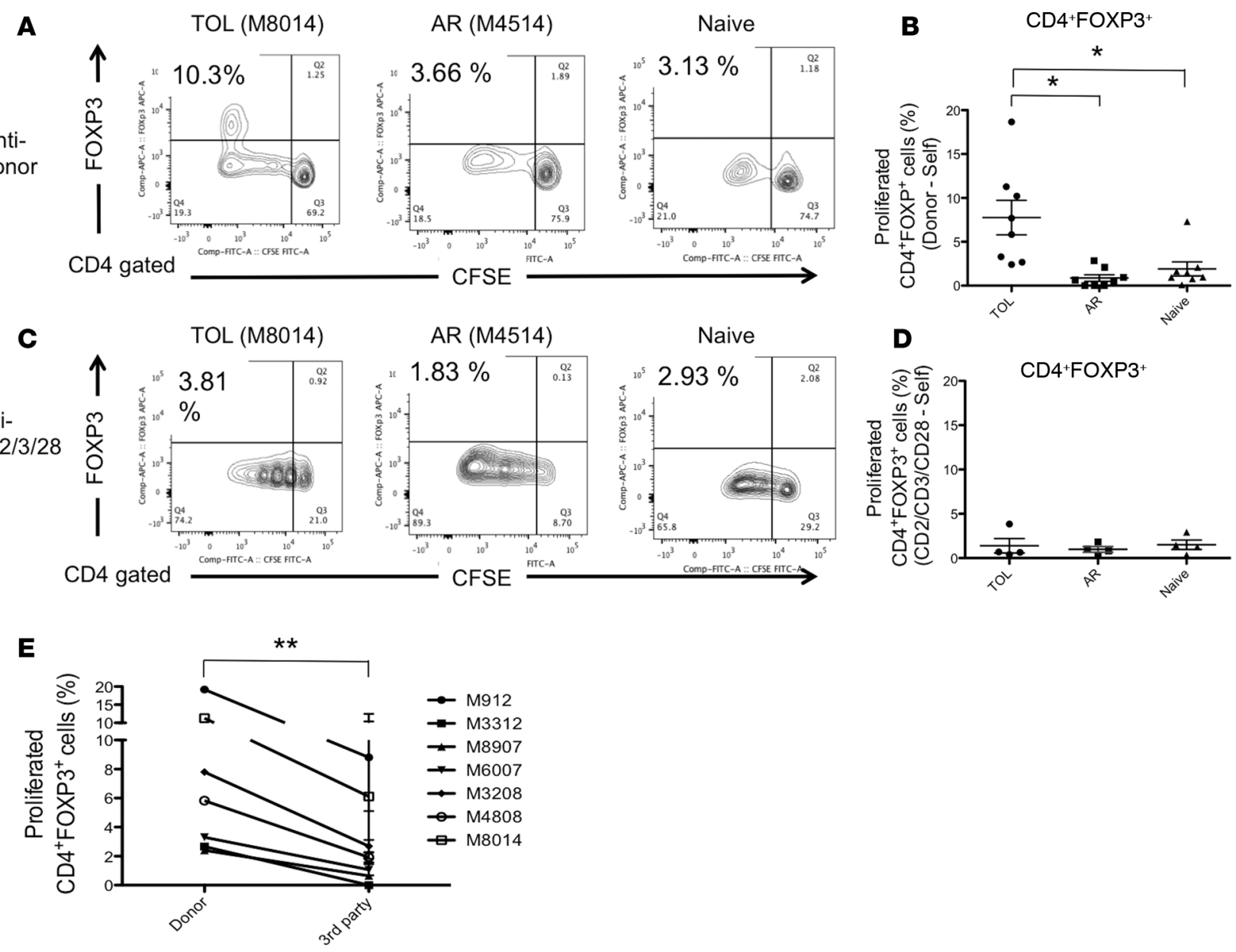

Figure 5. Allo-specific Treg expansion in tolerant recipients. $\mathrm{CD}^{+}$cells isolated from tolerant (TOL), acutely rejected (AR), and naive nonhuman primates (NHPs) were labeled with CFSE and were cultured with irradiated self, donor cells, or anti-CD2/CD3/CD28 mAbs for 5 days. Naive T cells were cultured with irradiated MHC-mismatched peripheral blood lymphocytes (PBLs). Cultured cells were then stained for CD4 and FOXP3. Representative flow cytometric data (A, anti-donor; C, anti-CD2/CD3/CD28) and mean of \% proliferation relative to the response to the self (B, anti-donor; $\mathbf{D}$, anti-CD2/CD3/CD28) are shown. Among these proliferated $\mathrm{CD} 4^{+}$cells after donor antigen stimulation, a significant proportion of proliferating $\mathrm{CD} 4^{+}$cells was $\mathrm{FOXP3^{+ }}$ in TOL, while such FOXP3 ${ }^{+}$cell proliferation was minimal in the AR and naive monkeys ( $\mathbf{A}$ and $\mathbf{B}$ ). This Treg expansion appeared alloantigen specific as Treg expansion was not observed by polyclonal stimulation with anti-CD2/CD3/CD28 mAbs (C and D). To examine whether Treg expansion is a donor-specific response, CFSE-labeled recipient PBLs from the TOL recipients $(n=7)$ were cultured with self, donor, and multiple third-party cells for 5 days, after which cultured cells were stained with FOXP3. Significantly greater FOXP3 ${ }^{+}$cell proliferation was observed after MLC with the donor PBLs than following stimulation with third-party PBLs (E). Proliferated cells (\%) = proliferated cells (\%) with donor, third-party antigens or anti-CD2/CD3/CD28 mAbs - proliferated cells (\%) with the self. These assays were performed at $520 \pm 86$ days in TOL recipients and $175 \pm 37$ days in AR recipients after bone marrow transplantation. Data are presented as the mean \pm SEM. ${ }^{*} P<0.05$, ANOVA and the Bonferroni multiple-comparison method was used to test for significant differences among 3 groups; $n=8$ (anti-donor) and $n=4$ (anti-CD2/CD3/CD28 mAbs) per group. ${ }^{* *} P<0.001, n=7$. For analysis of the donor-antigen specificity of Treg expansion, we conducted a 2-way ANOVA with factors of animal (experimental unit) and source of cell (donor or third parties).

anti-donor in vitro suppressive function in tolerant recipients only after priming with donor antigens (18, 29), we hypothesized that stimulation with donor antigens would also be necessary to detect the suppressive function of Tregs in tolerant NHPs. In TOL recipients, loss of an anti-donor CD8 ${ }^{+} \mathrm{T}$ cell response was consistently observed, although substantial anti-donor $\mathrm{CD} 4^{+} \mathrm{T}$ cell responses remained detectable. Nevertheless, a significant portion of these proliferated cells in TOL recipients consisted of $\mathrm{FOXP3}^{+}$, while FOXP3 ${ }^{-}$cells predominated in AR or naive NHPs. In addition, $\mathrm{FOXP}^{+}$cell expansion in TOL recipients was donor specific, as significantly greater $\mathrm{FOXP}^{+}$cell expansion was observed following donor versus third-party stimulation. More interestingly, these expanded Tregs were iTregs, which were converted from $\mathrm{CD}^{+}{ }^{+} \mathrm{CD} 25^{-} \mathrm{FOXP}^{-}{ }^{-}$non-Treg cells through allogeneic stimulation. These non-Treg cells were mixed populations of naive $\left(\mathrm{CD} 4^{+} \mathrm{CD} 95^{-} \mathrm{CD} 28^{+}\right)$, effector memory $\left(\mathrm{CD} 4^{+} \mathrm{CD} 95^{+} \mathrm{CD} 28^{-}\right)$, and central memory $\left(\mathrm{CD} 4^{+} \mathrm{CD} 95^{+} \mathrm{CD} 28^{+}\right) \mathrm{T}$ cells. Studies are currently underway to identify which non-Treg subset preferentially transformed to Tregs. 
A

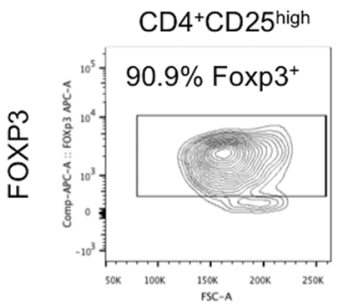

B MLC with donor PBMC (TOL)

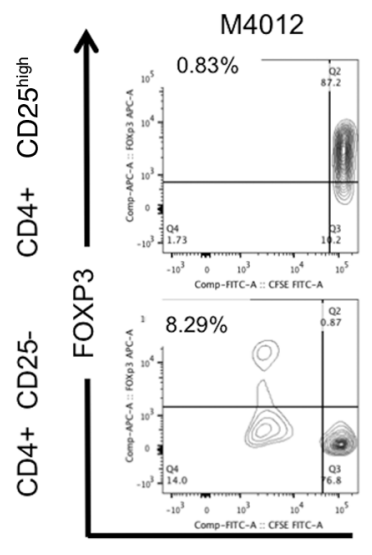

D MLC with donor PBMC (AR)

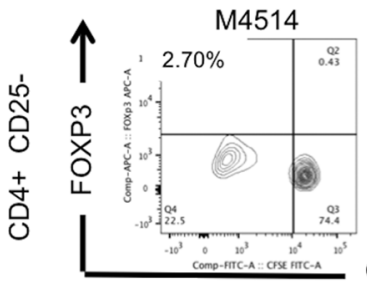

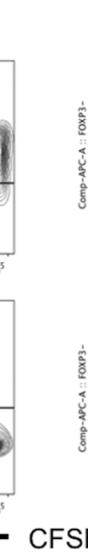

M3312
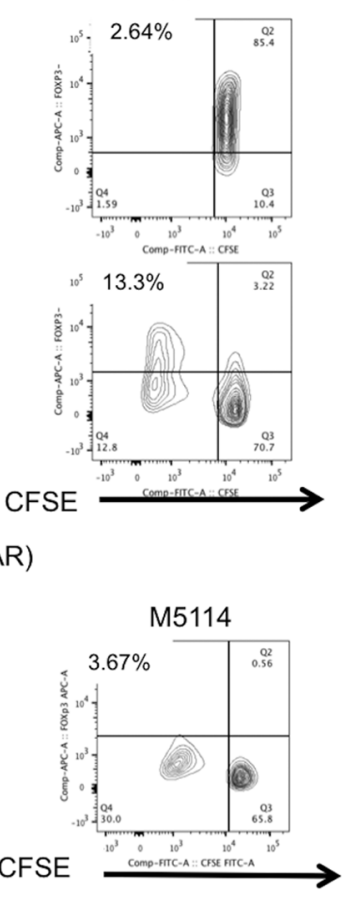

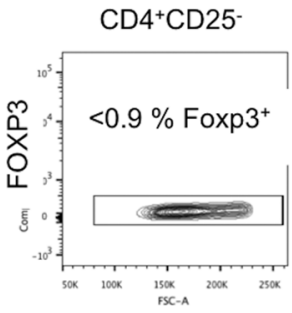

C MLC with anti-CD2/CD3/CD28 mAb (TOL)
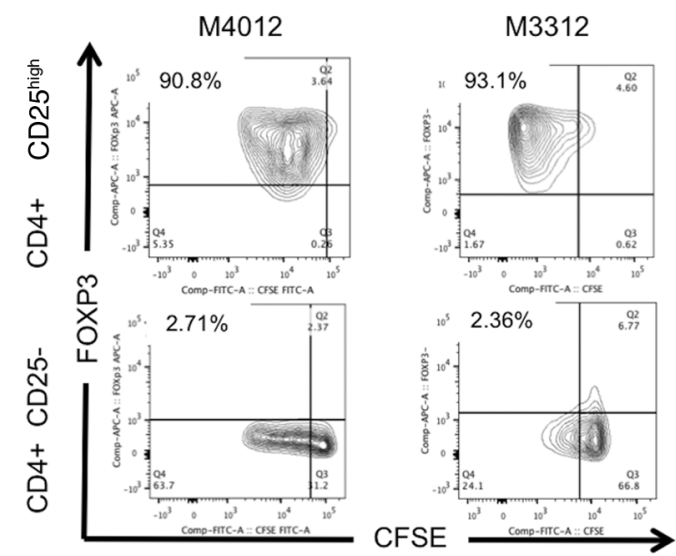

\section{$\mathbf{E}$}

MLC with anti-CD2/CD3/CD28 mAb (AR)
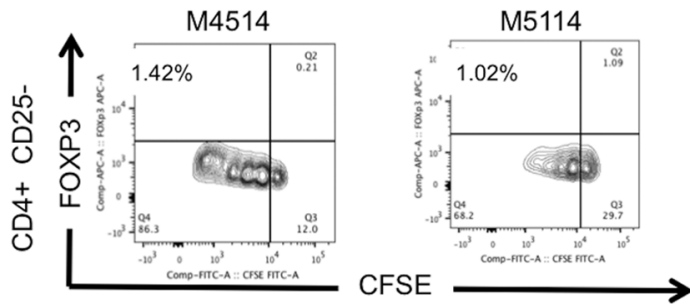

Figure 6. The expanded Tregs after donor stimulation were derived from non-Treg cells. The isolated CD4+CD25 high cells (Tregs) and CD4 ${ }^{+} \mathrm{CD} 25^{-}$cells (non-Tregs) from the tolerant (TOL) recipients (M4012: d299 pBMT and M3312: d441 pBMT) were labeled with CFSE and were cultured with irradiated donor peripheral blood lymphocytes (PBLs) or anti-CD2/CD3/CD28 mAbs in the presence of IL-2 (200 IU/ml). More than $90 \%$ of sorted CD4+CD25 high cells were FOXP3 positive (A, left panel) and less than $0.9 \%$ of $C D 4^{+} C D 25^{-}$cells were FOXP3 positive (A, right panel). While no significant FOXP3 ${ }^{+}$cell proliferation was observed in mixed lymphocyte culture (MLC) of CD4+CD25 high cells in either recipient (B, upper panels), substantial levels of FOXP3 ${ }^{+}$cells were detected from MLC of CD4+CD25- cells (B, lower panels). In sharp contrast, although significant FOXP3 ${ }^{+}$cell proliferation was observed in $\mathrm{CD}^{+}{ }^{+} \mathrm{CD} 25^{\text {high }}$ cells after polyclonal stimulation in both recipients (C, upper panels), no conversion from non-Treg to Treg was observed after polyclonal stimulation (C, lower panels). The isolated CD4+CD25 cells (non-Tregs) from the acute rejected recipients (AR) (M4514: d120 pBMT and M5114: d344 pBMT) were labeled with CFSE and were cultured with irradiated donor PBLs or anti-CD2/CD3/CD28 mAbs in the presence of IL-2 (200 IU/ml). Unlike TOL recipients, there was no conversion from non-Treg to Treg observed with both donor (D) and polyclonal stimulation (E). pBMT, post bone marrow transplantation.

In the functional assay of $\mathrm{T}$ cells after MLC, only the proliferating cells had a suppressive effect, supporting the notion that regulatory cells need to be primed with donor antigen in order to exhibit a suppressive function. These observations concur with our previous swine and human studies $(18,29)$, which demonstrate that PBLs from tolerant recipients do not inhibit naive anti-donor cytotoxic T lymphocyte responses in primary CML cultures, whereas PBLs primed with donor antigen do inhibit the generation of anti-donor cytotoxic T lymphocyte reactivity by naive PBLs (29).

Although recent studies have revealed considerable heterogeneity or plasticity in the Treg lineage (30), at least 2 major Treg subsets, natural (thymus-derived) Treg (nTreg) and iTreg, have been identified. In murine studies, iTregs were found to be inducible by donor splenocyte infusion with anti-CD4 mAb (31) or anti-CD40-ligand $\mathrm{mAb}$, suggesting that iTregs are likely generated when sufficient $\mathrm{T}$ cell costimulation is prevented by costimulatory blockade $(32,33)$. Similarly, our approach to tolerance induction requires sufficient donor antigen presentation by donor chimeric cells with concomitant costimulatory blockade, which may be analogous to the conditions required to generate iTregs. 
A $\mathrm{M} 8014$

Control

Anti-TGF- $\beta$

B $\mathrm{M} 8314$

Control

Anti-TGF- $\beta$
CD4 gated
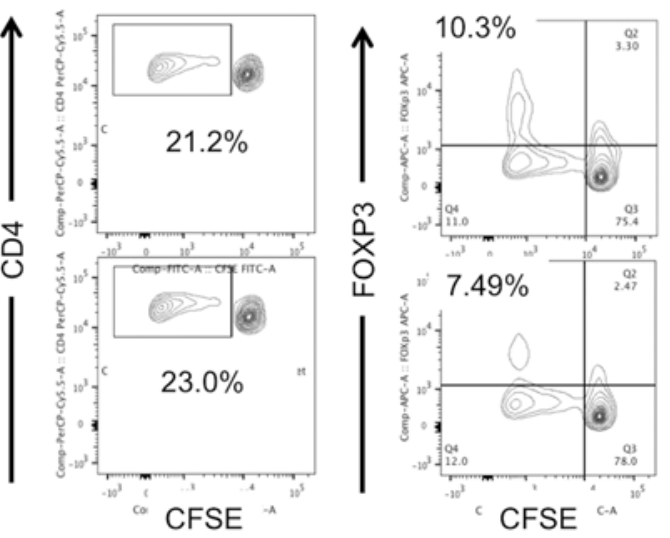

CD4 gated

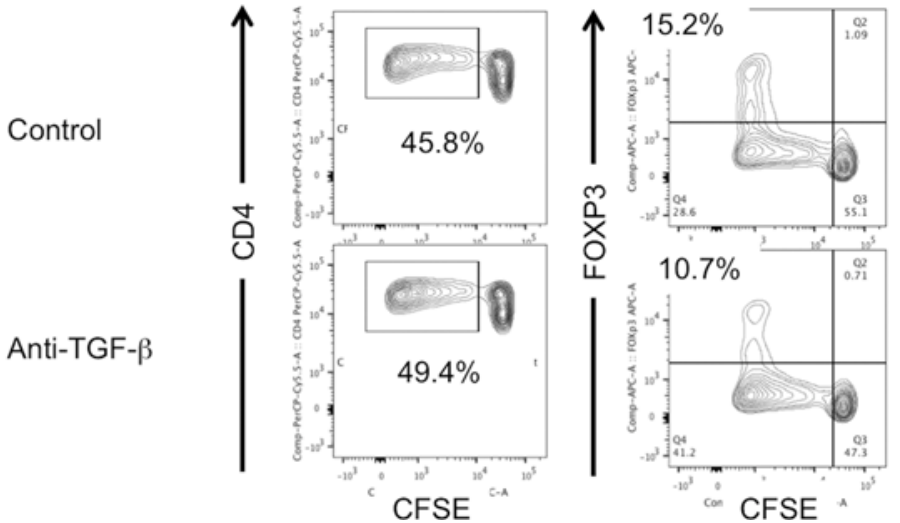

CD8 gated

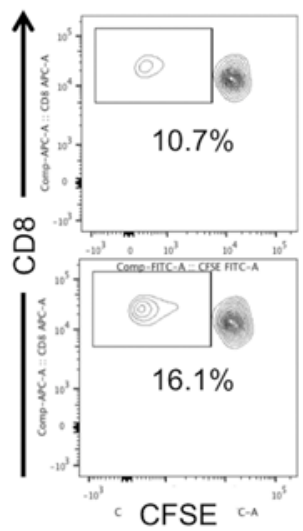

CD8 gated

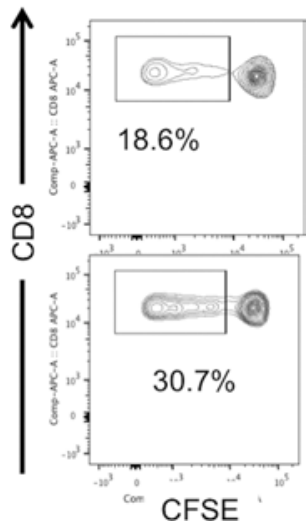

Figure 7. TGF- $\beta$ blockade inhibited Treg expansion and restored anti-donor $\mathrm{CD} 8$ responses. $\mathrm{CD}^{+}$ cells isolated from 2 tolerant (TOL) recipients, M8014: d212 pBMT (A) and M8314: d252 pBMT (B), were labeled with CFSE and cultured with irradiated donor peripheral blood lymphocytes in the presence of antiTCF- $\beta$ ( $50 \mathrm{mg} / \mathrm{ml}$ ) or isotype control monoclonal antibody $(50 \mathrm{mg} / \mathrm{ml})$ for 5 days. Cultured cells were then stained for CD4, CD8, and FOXP3. Although there was no difference in $\mathrm{CD}^{+} \mathrm{T}$ cell proliferation between anti-TCF- $\beta$ and isotype control (A and $\mathbf{B}$, left panels), TCF- $\beta$ blockade inhibited the Treg expansion in the 2 TOL recipients ( $\mathbf{A}$ and $\mathbf{B}$, middle panels). Furthermore, inhibition of Treg expansion by anti-TCF- $\beta$ blockade was associated with restoration of anti-donor $\mathrm{CD}^{+} \mathrm{T}$ cell responses in the 2 TOL recipients ( $\mathbf{A}$ and $\mathbf{B}$, right panels). pBMT, post bone marrow transplantation.

The current study revealed that iTreg expansion by donor antigen stimulation was inhibited by TGF- $\beta$ blockade, suggesting that TGF- $\beta$ is a critical cytokine for iTreg induction. Since some T cell subsets, such as Th3, have been shown to produce large amounts of TGF- $\beta$ (34), we hypothesize that donor-specific memory $\mathrm{T}$ cells, such as Th3, are generated in tolerant recipients and may produce sufficient amounts of TGF- $\beta$ upon encountering donor antigens, leading to conversion of naive $\mathrm{T}$ cells to iTregs. In vivo, these memory $\mathrm{T}$ cells can be activated when they encounter donor MHC class II antigens expressed on allograft endothelium (35, 36) or renal tubular epithelium (37) and produce TGF- $\beta$ locally. This may lead to conversion of naive T cells to Tregs in the renal allograft. Such local enrichment of Tregs in the renal allograft has been observed in our previous studies $(8,38)$ and may be critically important to protect the allograft from rejection.

Our studies demonstrate that allograft tolerance induced by transient chimerism is organ specific. Successful induction of allograft tolerance has been achieved in kidney and lung transplantation (4-6, $11,21,22)$, but not in isolated heart transplantation (24). We have shown that induction of heart allograft tolerance is possible with transient chimerism, if a kidney allograft from the same donor is cotransplanted (38). Therefore, intrinsic factors contributed by the kidney allograft in this model may also be critical for the enrichment of Tregs in the heart. In contrast to the heart, isolated lung allograft tolerance has been induced by transient chimerism, suggesting that the lung may also possess intrinsic factors similar to the kidney and hence be capable of locally expanding Tregs.

A clinical observation relevant to our findings has been reported by Syed et al. They detected similar antigen-reactive Treg expansion in patients with peanut allergy who achieved tolerance to peanuts after immunotherapy (39). In their study, PBLs from tolerant patients were cultured with peanuts or other allergens. After 7 days in culture, an increase of Tregs was observed with peanut, but not with other allergens. Although it was not shown whether nTregs or iTregs contributed to this specific suppression of allergic antigens, tolerant patients displayed specific Treg expansion after treatment, which may also suggest that it is possible to memorize tolerance to particular non-self antigens. 
A $\mathrm{M} 8907$

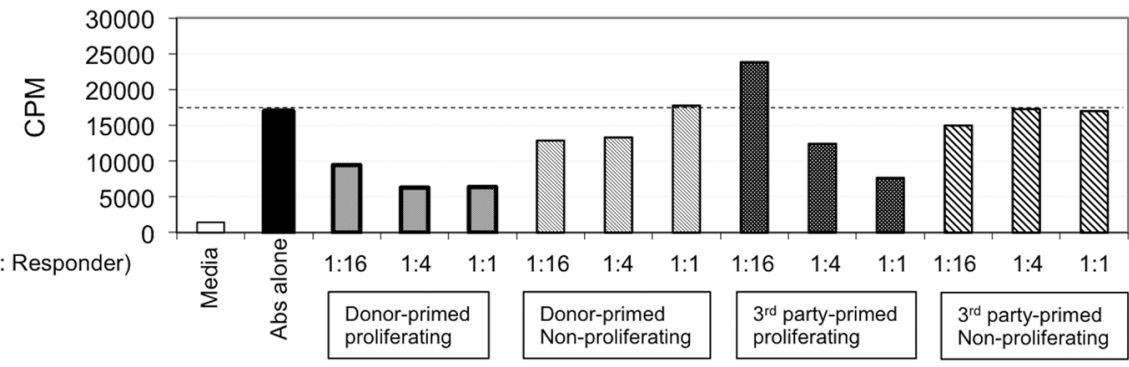

B M6007

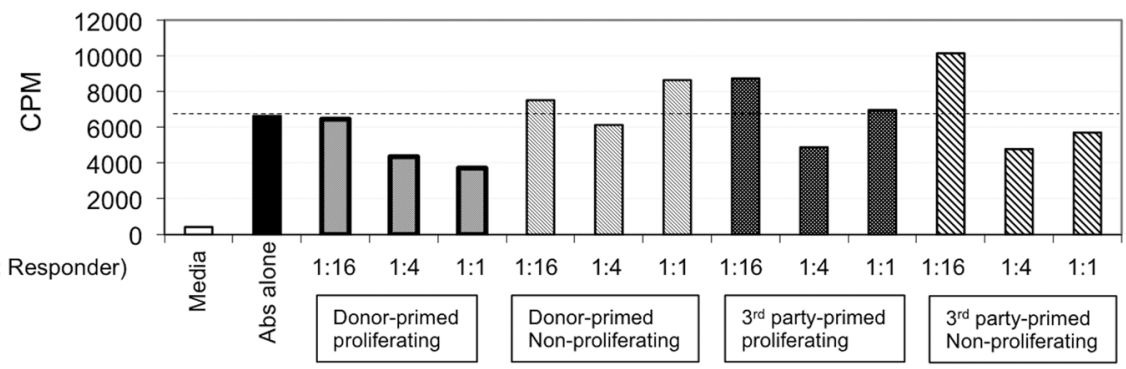

C $\mathrm{M} 8314$

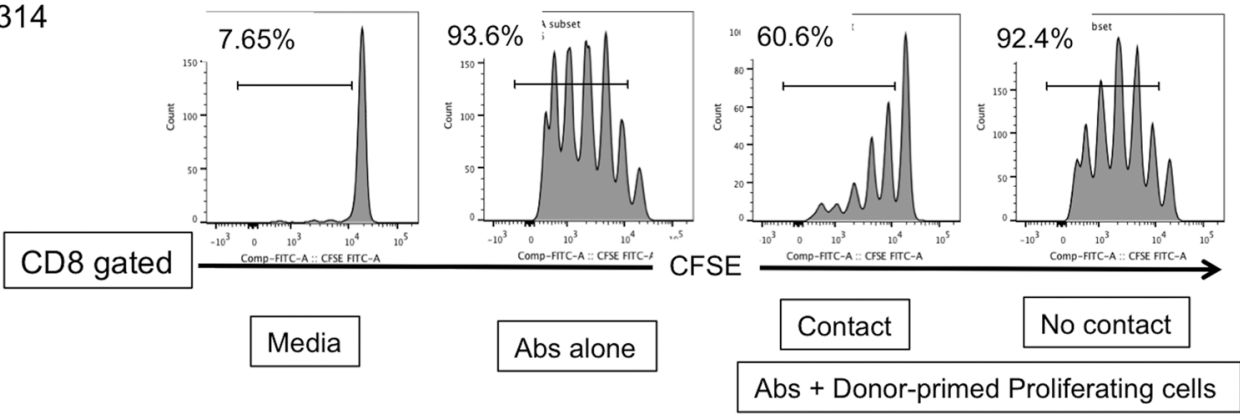

Figure 8. Peripheral blood lymphocytes of the tolerant recipients primed with donor antigens suppressed $\mathrm{T}$ cell activation. Peripheral blood lymphocytes (PBLs) from 3 recipients ,M8907: d821 pBMT (A), M6007: d930 pBMT (B), and M8314: d261 pBMT (C), in the tolerant (TOL) group were labeled with CFSE and cultured with irradiated donor or third-party PBLs. After 5 days of culture, CD4+CSFE ${ }^{\text {low }}$ (proliferating) and CD4+CSFE high (nonproliferating) cells were sorted and added at a varying ratio into the recipient $T$ cells in the presence of CD3/CD28 bead stimulation. (A and $\mathbf{B}$ ) A dosedependent suppression of T cell activation was observed by donor-primed proliferating (CSFE'ow) cells in both recipients. Although less significant, third-party-primed proliferating cells of a recipient (M8907) also showed a dose-dependent suppression of T cell activation (A). However, such a dose-dependent suppression by the third-party-primed cells was not observed in the other recipient (M6007) (B). Nonproliferating cells primed with either donor or third-party antigens

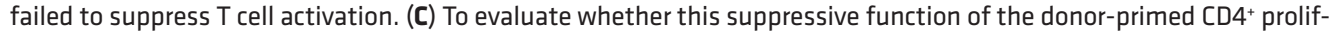
erating cells depends on cell-to-cell contact, isolated $\mathrm{CD}^{+}$cells from a TOL recipient (M8314) stained with CFSE were cultured with CD3/CD28 beads. Donor-primed proliferating CD4+ (CSFE ${ }^{\text {low) }}$ cells were added directly (contact) or seeded onto Transwell permeable support cell culture inserts (no contact). Since CD4 ${ }^{+}$cells consisted of both responder CD4+ cells and modulator $\mathrm{CD} 4^{+}$cells in this experiment, T cell activation was evaluated by $\mathrm{CD} 8^{+}$cell proliferation. The ratio of responder to modulator was 1 to 1 . Although inhibition of $C D 8^{+}$cell activation was observed by cell-to-cell contact, such inhibition was not observed in the Transwell system, which suggested that direct cell-to-cell contact is required for suppressive function of donor-primed modulator cells. pBMT, post bone marrow transplantation.

This study, which demonstrates decreased CD8 responses in tolerant NHPs, despite persistent CD4 anti-donor responses due to donor-specific expansion of Tregs, provides support for the hypothesis that specific induction of iTregs by donor antigens is key to long-term allograft tolerance induced by transient mixed chimerism. Additional studies will be necessary to conclude whether the suppressive function of iTregs was donor specific, since CD3/CD28 bead-induced $\mathrm{T}$ cell activation was used to evaluate the suppressive function of iTregs. However, since expansion of iTregs was donor specific, one could presume that the eventual suppressive effects in vivo would also be donor specific. These data suggest that peripheral regulatory mechanisms, rather than central deletion, are responsible for the maintenance of allograft tolerance in NHPs. Further studies to identify which of the T cell subsets regulates iTreg conversion are in progress. 


\section{Methods}

Animals. Cynomolgus monkeys weighing 4-7 kg were used (Charles River Primates). Nine monkeys that had achieved long-term (>250 days) allograft survival without maintenance immunosuppression (kidney $[n=7]$, lung $[n=2]$ ) (TOL) were investigated. M3312 and M4012 shared 1 haplotype with the donor MHC. MHC genotypes of the other 5 recipients were fully mismatched with the donor MHC genotypes. To compare immunologic responses with the TOL recipients, 5 kidney transplant recipients and 3 heterotopic heart recipients that received the same conditioning regimen and DBMT but rejected their allografts were included (Table 1 and Figure 1).

Cynomolgus MHC genotyping. MHC characterization was performed as previously described (40, 41). Briefly, genomic DNA was prepared from PBMCs and splenocytes. Panels of 17 microsatellite loci spanning $\sim 5 \mathrm{Mb}$ of the MHC region were amplified from the genomic DNA with fluorescent-labeled PCR primers and fragment size analysis was determined. The microsatellite haplotypes for each animal were converted to predicted MHC genotypes based on previous cloning and sequencing work with cynomolgus monkeys $(40,41)$.

Organ and bone marrow transplantation. The procedures and the conditioning regimens were performed as described previously (4-6, 11, 22, 24, 42, 43). The kidney, lung, and heart allograft recipients received DBMT either simultaneously or 4 months after organ transplantation. Briefly, these recipients received a nonmyeloablative conditioning regimen that consisted of total body irradiation with $1.5 \mathrm{~Gy} \times 2$ on days -6 and -5 (relative to DBMT), thymic irradiation with 7 Gy on day -1 , pretransplant anti-thymocyte globulin with or without anti-CD $8 \mathrm{mAb}$, and DBMT on day 0 followed by anti-CD154 mAb (20 mg/kg on days 0 and 2 followed by $10 \mathrm{mg} / \mathrm{kg}$ on days 5, 7, 9, and 12 after DBMT) or CTLA4Ig (20 mg/ $\mathrm{kg}$ on days 0, 2, 5, and 15 after DBMT), and a 1-month post-transplant course of cyclosporine. No immunosuppression was administered after 1 month. M4808 also received $10 \mathrm{mg} / \mathrm{kg}$ of rituximab on days $-14,-7$, and 0 in addition to the conditioning regimen described above.

Flow cytometric analyses and detection of chimerism. PBMCs, either isolated from the peripheral blood or harvested after a 5-day MLC, were analyzed via cell-surface staining using CD3 (SP34), CD4 (L200), CD8 (SK1), CD20 (2H7), CD25 (M-A251) (all BD Pharmingen), CD16 (NKP15, BD Biosciences), and NKG2a (Z199, Beckman Coulter) antibodies. For chimerism analyses, we used an anti-MHC class I HLA mAb (H38, One Lambda, Inc.) that reacts specifically with an MHC class I antigen on donor but not recipient cells. To assess intracellular protein expression of FOXP3, cells were permeabilized using Fixation/Permeabilization solution (eBioscience) and then stained with anti-FOXP3 mAb (PCH101, BD Pharmingen). Cells were analyzed on a FACSverse (BD Biosciences) or Accuri Flow Cytometer (BD Biosciences) using FlowJo software (FLOWJO LLC).

Mixed lymphocytes culture. T cells were purified by negative selection with a Pan T Cell Isolation Kit (Miltenyi Biotec). $\mathrm{CD} 4^{+} \mathrm{T}$ cells were sorted into Tregs $\left(\mathrm{CD} 4^{+} \mathrm{CD} 25^{\text {high }}\right)$ and non-Tregs $\left(\mathrm{CD} 4^{+} \mathrm{CD} 25^{-}\right)$using a FACSAria cell sorter (BD Biosciences). The isolated T cells, $\mathrm{CD} 4^{+} \mathrm{CD} 25^{\text {high }}$ cells, and $\mathrm{CD} 4^{+} \mathrm{CD} 25^{-}$cells were labeled with CFSE (Life Technologies) at a concentration of $3 \mu \mathrm{M}$ per $10^{7}$ cells at $37^{\circ} \mathrm{C}$ for 5 minutes and cultured in 96-well V-bottom plates with irradiated PBMCs or T cell activation beads $(\alpha \mathrm{CD} 2 / \alpha \mathrm{CD} 3 /$ $\alpha \mathrm{CD} 28 \mathrm{mAb}$ ) (Miltenyi Biotec). In experiments to identify the origin of Tregs, human IL-2 (200 IU/ml) (BD Biosciences) was added to the MLC. For TGF- $\beta$ blockade, anti-TGF- $\beta$ monoclonal antibody $(50 \mu \mathrm{g} / \mathrm{ml})$ (1D11.16.8, Bio X Cell) and IgG1 isotype control monoclonal antibody (50 $\mu \mathrm{g} / \mathrm{ml}$ ) (MOPC-21, Bio X Cell) were used. After 5 days, cells were stained with antibodies and CFSE dilution was assessed by flow cytometry.

Assay for $T$ cell suppressive function. CFSE-labeled cells from TOL monkeys were cultured with irradiated donor or third-party PBMCs. After 4 days, cells were harvested and sorted on the FACSAria into $\mathrm{CD}^{+} \mathrm{CFSE}^{\text {low }}$ (nonproliferating) and $\mathrm{CD} 4^{+} \mathrm{CFSE}^{\text {high }}$ (proliferating) cells. PBLs isolated from TOL animals (stained with or without CFSE) were cultured in a 96-well or 24-well round bottom plate with stimulation of plate-bound anti-CD3 Ab (SP34, $10 \mu \mathrm{g} / \mathrm{ml}$, BD Pharmingen) and soluble anti-CD28 mAb (28.2, $10 \mu \mathrm{g} / \mathrm{ml}$, BD Pharmingen). Donor-primed or third-party-primed, $\mathrm{CD} 4^{+}$proliferating or $\mathrm{CD}^{+}$nonproliferating cells were added as modulators at varying ratios. In some experiments, these sorted cells were seeded onto 24-well Transwell permeable support cell culture inserts (Corning). The cells were cultured for 4 days. During the last 24 hours, the plates were pulsed with $1 \mu \mathrm{Ci} /$ well ${ }^{3} \mathrm{H}$-thymidine (Dupont) and its uptake was quantified in a beta counter. Results were expressed as stimulation index (SI) ratios, which were the mean cpm of experimental/autologous stimulators. The cells stained with CFSE were cultured for 5 days and stained with CD8 antibody. CFSE dilution was assessed by flow cytometry. 
Statistics. ANOVA and the Bonferroni multiple-comparison method were used to test for significant differences among 3 groups using GraphPad Prism 5 (Graphpad Software, Inc.). For analysis for the donor antigen specificity of Treg expansion, we conducted a 2-way ANOVA with factors of animal (experimental unit) and source of cell (donor or third parties). All tests were 2-sided and $P$ less than 0.05 was considered statistically significant.

Study approval. All surgical procedures and postoperative care of animals were performed in accordance with National Institutes of Health guidelines for the care and use of primates and were approved by the Massachusetts General Hospital Institutional Animal Care and Use Committee.

\section{Author contributions}

$\mathrm{KH}$ and AA designed and performed experiments, analyzed the data, and wrote the manuscript. TO, YY, MT, KHH, KK, JSA, and JCM performed the experiments. DS contributed to statistical design. RNS and RBC performed the pathological analysis. GB, DHS, and ABC supervised the experiments. TK designed and supervised experiments, analyzed data, and wrote the manuscript.

\section{Acknowledgments}

We appreciate the editorial assistance of Ann S. Adams. The present work was supported in part by grants from the National Institute of Allergy and Infectious Disease (NIAID) U19 AI102405-01 and U01AI094374, and the National Heart, Lung and Blood Institute (NHLBI) P01HL018646.

Address correspondence to: Tatsuo Kawai, Department of Surgery, Center for Transplantation Sciences, Harvard Medical School at the Massachusetts General Hospital, Boston, Massachusetts 02114, USA. Phone: 617.726.0289, E-mail: TKAWAI@mgh.harvard.edu.

1. Sayegh MH, Carpenter CB. Transplantation 50 years later--progress, challenges, and promises. $N$ Engl J Med. 2004;351(26):2761-2766.

2. Pascual M, Theruvath T, Kawai T, Tolkoff-Rubin N, Cosimi AB. Strategies to improve long-term outcomes after renal transplantation. NEngl J Med. 2002;346(8):580-590.

3. Lamb KE, Lodhi S, Meier-Kriesche HU. Long-term renal allograft survival in the United States: a critical reappraisal. Am $J$ Transplant. 2011;11(3):450-462.

4. Kawai T, et al. Mixed allogeneic chimerism and renal allograft tolerance in cynomolgus monkeys. Transplantation. 1995;59(2):256-262.

5. Kawai T, et al. CD154 blockade for induction of mixed chimerism and prolonged renal allograft survival in nonhuman primates. Am J Transplant. 2004;4(9):1391-1398.

6. Yamada Y, et al. Use of CTLA4Ig for induction of mixed chimerism and renal allograft tolerance in nonhuman primates. $A m$ J Transplant. 2014;14(12):2704-2712.

7. Spitzer TR, et al. Combined histocompatibility leukocyte antigen-matched donor bone marrow and renal transplantation for multiple myeloma with end stage renal disease: the induction of allograft tolerance through mixed lymphohematopoietic chimerism. Transplantation. 1999;68(4):480-484.

8. Kawai T, et al. HLA-mismatched renal transplantation without maintenance immunosuppression. N Engl J Med. 2008; 358(4):353-361.

9. Kawai T, Sachs DH, Sykes M Cosimi AB. HLA-mismatched renal transplantation without maintenance immunosuppression. NEngl J Med. 2013; 368(19):1850-1852.

10. Kawai T, et al. Long-term results in recipients of combined HLA-mismatched kidney and bone marrow transplantation without maintenance immunosuppression. Am J Transplant. 2014;14(7):1599-1611.

11. Tonsho M, et al. Tolerance of lung allografts achieved in nonhuman primates via mixed hematopoietic chimerism. Am J Transplant. 2015;15(8):2231-2239.

12. Sharabi Y, Sachs DH. Mixed chimerism and permanent specific transplantation tolerance induced by a nonlethal preparative regimen. J Exp Med. 1989;169(2):493-502.

13. Tomita Y, Khan A, Sykes M. Role of intrathymic clonal deletion and peripheral anergy in transplantation tolerance induced by bone marrow transplantation in mice conditioned with a nonmyeloablative regimen. J Immunol. 1994;153(3):1087-1098.

14. Khan A, Tomita Y, Sykes M. Thymic dependence of loss of tolerance in mixed allogeneic bone marrow chimeras after depletion of donor antigen. Peripheral mechanisms do not contribute to maintenance of tolerance. Transplantation. 1996;62(3):380-387.

15. Manilay JO, Pearson DA, Sergio JJ, Swenson KG, Sykes M. Intrathymic deletion of alloreactive T cells in mixed bone marrow chimeras prepared with a nonmyeloablative conditioning regimen. Transplantation. 1998;66(1):96-102.

16. Adams AB, et al. Heterologous immunity provides a potent barrier to transplantation tolerance. J Clin Invest. 2003;111(12):1887-1895.

17. Seok J, et al. Genomic responses in mouse models poorly mimic human inflammatory diseases. Proc Natl Acad Sci USA. 2013;110(9):3507-3512.

18. Andreola G, et al. Mechanisms of donor-specific tolerance in recipients of haploidentical combined bone marrow/kidney trans- 
plantation. Am J Transplant. 2011;11(6):1236-1247.

19. Morris H, et al. Tracking donor-reactive T cells: evidence for clonal deletion in tolerant kidney transplant patients. Sci Transl Med. 2015; 7(272):272ra210

20. Yamada Y, et al. Repeated injections of IL-2 break renal allograft tolerance induced via mixed hematopoietic chimerism in monkeys. Am J Transplant. 2015;15(12):3055-3066.

21. Lee $\mathrm{S}$, et al. Alefacept promotes immunosuppression-free renal allograft survival in nonhuman primates via depletion of recipient memory T cells. Am J Transplant. 2013;13(12):3223-3229.

22. Koyama I, et al. Depletion of CD8 memory T cells for induction of tolerance of a previously transplanted kidney allograft. Am J Transplant. 2007;7(5):1055-1061.

23. Yamada Y, et al. Overcoming memory T-cell responses for induction of delayed tolerance in nonhuman primates. Am J Transplant. 2012;12(2):330-340.

24. Kawai T, et al. Effect of mixed hematopoietic chimerism on cardiac allograft survival in cynomolgus monkeys. Transplantation. 2002;73(11):1757-1764.

25. Bestard O, et al. Presence of FoxP $3^{+}$regulatory T cells predicts outcome of subclinical rejection of renal allografts. $J A m$ Soc Nephrol. 2008;19(10):2020-2026.

26. Krystufkova E, Sekerkova A, Striz I, Brabcova I, Girmanova E, Viklicky O. Regulatory T cells in kidney transplant recipients: the effect of induction immunosuppression therapy. Nephrol Dial Transplant. 2012;27(6):2576-2582.

27. Zuber J, et al. FOXP3-enriched infiltrates associated with better outcome in renal allografts with inflamed fibrosis. Nephrol Dial Transplant. 2009;24(12):3847-3854.

28. LoCascio SA, et al. Mixed chimerism, lymphocyte recovery, and evidence for early donor-specific unresponsiveness in patients receiving combined kidney and bone marrow transplantation to induce tolerance. Transplantation. 2010;90(12):1607-1615.

29. Ierino FL, Yamada K, Hatch T, Rembert J, Sachs DH. Peripheral tolerance to class I mismatched renal allografts in miniature swine: donor antigen-activated peripheral blood lymphocytes from tolerant swine inhibit antidonor CTL reactivity. J Immunol. 1999;162(1):550-559.

30. Sawant DV, Vignali DA. Once a Treg, always a Treg?. Immunol Rev. 2014;259(1):173-191.

31. Kingsley CI, Karim M, Bushell AR Wood KJ. CD25+CD4+ regulatory T cells prevent graft rejection: CTLA-4- and IL-10-dependent immunoregulation of alloresponses. J Immunol. 2002; 168(3):1080-1086.

32. Burrell BE, Bromberg JS. Fates of $\mathrm{CD}^{+} \mathrm{T}$ cells in a tolerant environment depend on timing and place of antigen exposure. $A m$ J Transplant. 2012;12(3):576-589.

33. Pinelli DF, et al. An anti-CD154 domain antibody prolongs graft survival and induces Foxp3(+) iTreg in the absence and presence of CTLA-4 Ig. Am J Transplant. 2013;13(11):3021-3030.

34. Carrier Y, Yuan J, Kuchroo VK Weiner HL. Th3 cells in peripheral tolerance. I. Induction of Foxp3-positive regulatory T cells by Th3 cells derived from TGF-beta T cell-transgenic mice. J Immunol. 2007; 178(1):179-185.

35. Muczynski KA, Ekle DM, Coder DM, Anderson SK. Normal human kidney HLA-DR-expressing renal microvascular endothelial cells: characterization, isolation, and regulation of MHC class II expression. J Am Soc Nephrol. 2003;14(5):1336-1348.

36. Shiao SL, Kirkiles-Smith NC, Shepherd BR, McNiff JM, Carr EJ, Pober JS. Human effector memory CD4 ${ }^{+}$T cells directly recognize allogeneic endothelial cells in vitro and in vivo. J Immunol. 2007;179(7):4397-4404.

37. Wuthrich RP, Glimcher LH, Yui MA, Jevnikar AM, Dumas SE, Kelley VE. MHC class II, antigen presentation and tumor necrosis factor in renal tubular epithelial cells. Kidney Int. 1990;37(2):783-792.

38. Tonsho M, et al. Successful tolerance induction of cardiac allografts in nonhuman primates through donor kidney co-transplantation [2013 American Transplant Congress abstract 490]. Am J Transplant. 2013; 13(Supp1 5).

39. Syed A, et al. Peanut oral immunotherapy results in increased antigen-induced regulatory T-cell function and hypomethylation of forkhead box protein 3 (FOXP3). J Allergy Clin Immunol. 2014;133(2):500-510.

40. O'Connor SL, et al. Comprehensive characterization of MHC class II haplotypes in Mauritian cynomolgus macaques. Immunogenetics. 2007;59(6):449-462.

41. Pendley CJ, et al. MHC class I characterization of Indonesian cynomolgus macaques. Immunogenetics. 2008; 60(7):339-351.

42. Cosimi AB, et al. Prolonged survival of nonhuman primate renal allograft recipients treated only with anti-CD4 monoclonal antibody. Surgery. 1990;108(2):406-13; discussion 413.

43. Aoyama A, et al. Long-term lung transplantation in nonhuman primates. Am J Transplant. 2015;15(5):1415-1420. 